\begin{tabular}{|l|l|l|}
\hline \multicolumn{2}{|c|}{ PublisherInfo } \\
\hline \hline PublisherName & $:$ & BioMed Central \\
\hline \hline PublisherLocation & $:$ & London \\
\hline \hline PublisherImprintName & $:$ & BioMed Central \\
\hline \hline
\end{tabular}

\title{
The problem of trastuzumab (Herceptin) resistance: a role for
} IGF-1R?

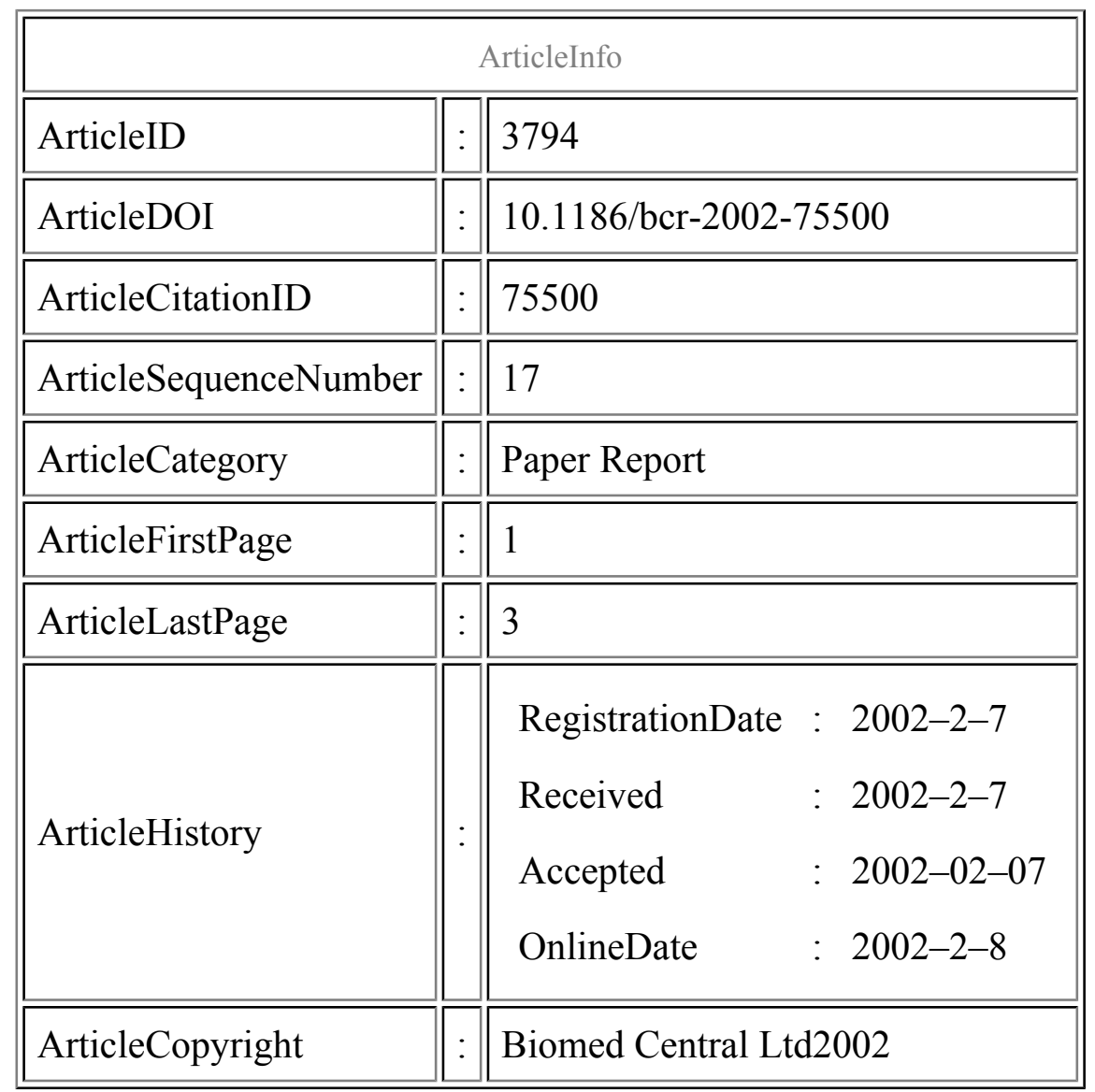




\begin{tabular}{|l|l|l||}
\hline ArticleGrants & $:$ & \\
\hline \hline ArticleContext & $:$ & 1305844 \\
\hline
\end{tabular}

Julia MW Gee, ${ }^{\text {Aff1 }}$

Aff1 Tenovus Centre for Cancer Research, Welsh School of Pharmacy, Cardiff University, Wales, UK

\section{Keywords}

Breast cancer, HER2, IGF-1R, resistance, trastuzumab (Herceptin)

\section{Context}

An increasingly fruitful avenue in cancer therapeutics is the use of agents targeting signal transduction pathways. Trastuzumab (Herceptin), a humanised monoclonal antibody directed against the tyrosine kinase receptor HER2, is one such agent that is proving valuable in the treatment of HER2-overexpressing breast cancer. Unfortunately, responses to trastuzumab vary in magnitude and can also be short lived. These clinical limitations result from acquisition of trastuzumab resistance by the cancer cells. Elucidation of the signal transduction mechanisms underlying resistance would potentially indicate new therapeutic strategies to prevent or delay the resistant state. The present in vitro study investigates whether signalling initiated by the insulin-like growth factor-1 receptor (IGF-1R), an additional tyrosine kinase receptor important in breast neoplasia, enables breast cancer cells to resist trastuzumab inhibition.

\section{Significant findings}

Human breast cancer cells overexpressing HER2 with substantial activated IGF-1R (MCF-7/ HER2-18) were not inhibited by trastuzumab in the presence of increased serum or IGF-1. Trastuzumab was antiproliferative in such cells only when IGF-1R signalling was minimised. In contrast, cells overexpressing HER2 alone (e.g. SKBR3) were highly sensitive to inhibition of proliferation of trastuzumab irrespective of serum or IGF-1. Trastruzumab inhibition of SKBR3 was associated with increased G1 fraction, reduced cyclin $\mathrm{E}$ and increased $\mathrm{p} 27^{\mathrm{Kip} 1}$. SKBR3 cells became resistant to trastuzumab in the presence of IGF-1 following IGF-1R transfection (SKBR3/IGF-1R), an event that prevented trastuzumab induction of $\mathrm{p} 27^{\mathrm{Kip} 1}$ and minimised the $\mathrm{G} 1$ fraction and cyclin $\mathrm{E}$ decline. 
Challenge with IGF binding protein 3 again restored growth suppressive activity of trastuzumab. The authors conclude that in breast cancer cells overexpressing HER2, increased IGF-1R signalling interferes with trastuzumab response, suggesting that anti-IGF-1R strategies may be appropriate in trastuzumab resistance.

\section{Comments}

This study is the first associating increased IGF-1R signalling with perturbation of trastuzumab response, data with interesting implications for the design of therapeutic strategies to prevent or delay trastuzumab resistance. The observations provide a further demonstration of the "plasticity" of the neoplastic breast cell in its ability to recruit additional signal transduction pathways for growth when challenged with inhibitory agents. As the authors state, the influence of IGF-1R on trastuzumab response in HER2 positive patients must now be addressed, while future research should detail the complex hierarchical interactions between these receptors. Finally, while this study has shed light on one potential mechanism of trastuzumab resistance, the clinical frequency of this phenomenon suggests it would be prudent to extend such studies to additional growth factors.

\section{Methods}

Cell culture, transfection, MTT assay, colony forming assay, flow cytometry, western blotting, immunoprecipitation

\section{Additional information}

Albanell J, Baselga J: Unraveling resistance to trastuzumab (Herceptin): insulin-like growth factor-1 receptor, a new suspect. J Natl Cancer Inst 2001, 93: 1830-1831

\section{References}

1. Lu Y, Zi X, Zhao Y, Mascarenhas D, Pollak M: Insulin-like growth factor-I receptor signaling and resistance to trastuzumab (Herceptin). J Natl Cancer Inst. 2001, 93: 1852-1857.

This PDF file was created after publication. 